\title{
Three-Dimensional Audio-Magnetotelluric Imaging including Surface Topography of the Cimabanshuo Porphyry Copper Deposit, Tibet
}

\author{
Ping Qi, Yaotian Yin *, Sheng Jin, Wenbo Wei, Liuyang Xu, Hao Dong and Jinhui Huang
}

check for updates

Citation: Qi, P.; Yin, Y.; Jin, S.; Wei, W.; Xu, L.; Dong, H.; Huang, J.

Three-Dimensional Audio-

Magnetotelluric Imaging including

Surface Topography of the

Cimabanshuo Porphyry Copper

Deposit, Tibet. Minerals 2021, 11, 1424

https://doi.org/10.3390/

$\min 11121424$

Academic Editor: Michael S. Zhdanov

Received: 10 November 2021

Accepted: 14 December 2021

Published: 16 December 2021

Publisher's Note: MDPI stays neutral with regard to jurisdictional claims in published maps and institutional affiliations.

Copyright: (c) 2021 by the authors. Licensee MDPI, Basel, Switzerland. This article is an open access article distributed under the terms and conditions of the Creative Commons Attribution (CC BY) license (https:// creativecommons.org/licenses/by/ $4.0 /)$.
School of Geophysics and Information Technology, China University of Geosciences, Beijing 100083, China; 2010200020@cugb.edu.cn (P.Q.); jinshengcugb@hotmail.com (S.J.); 2016010042@cugb.edu.cn (W.W.); 3010190002@cugb.edu.cn (L.X.); donghao@cugb.edu.cn (H.D.); 2110190057@cugb.edu.cn (J.H.)

* Correspondence: yaotian@cugb.edu.cn; Tel.: +86-(010)-82321906

\begin{abstract}
Cimabanshuo deposit is a newly discovered porphyry copper $(\mathrm{Cu})$ deposit with giant metallogenic potential, found in the western segment of the Gangdese metallogenic belt, Tibet. The average elevation of the deposit is greater than $5500 \mathrm{~m}$ and the terrain on which it is found is steep and complex. Therefore, it is untraversed, and the existing exploration works on it are weak. We used 59 AMT sites belonging to an array covering the main, proven mineralization zone and ore bodies of this deposit for an analysis of its underground electrical structure. Dimensionality and strike analysis revealed the apparent three-dimensional (3D) features near the $\mathrm{Cu}$ ore bodies. 3D inversion with topography was conducted for the AMT array data. A large range of high-resistivity anomaly ( 500-2000 $\Omega \mathrm{m})$ appears beneath the proven $\mathrm{Cu}$ mineralization zone and ore bodies, which is interpreted as intrusive rocks with potassic alteration. Although containing chalcopyrite, it is characterized by middle-high resistivity due to a low sulfide content and poor connectivity. Moreover, a series of scattered conductors $(\sim 10-300 \Omega \mathrm{m})$ around the $\mathrm{Cu}$ ore bodies are distributed in the shallow layer from near the surface to $\sim 200 \mathrm{~m}$, possibly indicating phyllic alteration containing pyritization and connected metal sulfides. The proven ore bodies of Cimabanshuo are mainly located at the junction regions between high-resistivity intrusive rocks and high-conductivity sericitization alteration zones. According to this research, the 3D inversion with topography of AMT data can visually display the 3D distribution of intrusive rocks and alteration zones beneath porphyry $\mathrm{Cu}$ deposits in high-elevation regions, and provides a reference for further exploration works.
\end{abstract}

Keywords: audio-frequency magnetotelluric soundings; Gangdese metallogenic belt; hydrothermal alteration; metallogenic mechanism; mineral exploration

\section{Introduction}

The formation of porphyry copper deposits is generally considered to be related to the hydrothermal fluids released by magma generated within subduction zones [1,2]. The arc magma, being rich in $\mathrm{Cu}$ and other metals $(\mathrm{Mo} \pm \mathrm{Au}$ ) and saturated with volatiles and salt water, intrude into the upper and middle crust [3]. Finally, the metallic elements precipitate in the form of metal sulfides. Upon cooling down, they react with the wall rock to cause the chalcopyrite and molybdenite precipitating within quartz veins and being disseminated in potassic-altered rocks. As the fluids rise and cool down further, they become more acidic, resulting in the alteration of foliaceous (quartz-sericite-pyrite), argillaceous and high-grade argillaceous (such as clay, alunite, residual quartz) [4]. Therefore, the alteration and mineral sulfides of the porphyry copper deposit system could show typical zoning characteristics both in vertical and lateral directions centered on the shallow volcanic intrusive complex (Figure 1) [5]. After the above mineralization processes, subsequent regional tectonic movements, such as uplift, result in the gradual denudation of shallow hydrothermal alteration zones and volcanic rocks, causing the outcrop of underlying secondary volcanic 
rocks, porphyry mineralization and batholith, which could also make the actual porphyry $\mathrm{Cu}$ system more diverse and complicated [4].

These porphyry $\mathrm{Cu}$ deposits exposed to the surface have mostly been discovered and mined in large porphyry $\mathrm{Cu}$ provinces around the world, such as the Canadian Cordillera, Andean orogenic belt in Chile, and Gangdese belt in Tibet [4,6,7], but mineralogists still believe that the concealed deposits have equally ideal ore-forming potentials [8]. This makes it very important to image and explore the underground structure of these deposits. In addition to the drilling works, which can directly obtain the underground lithological distribution, geophysical surveys are also proved to be effective for exploring such deposits due to the different physical properties between mineralization, alteration and surrounding rocks [9]. Based on the results of laboratory measurements and practical exploration works [10,11], a generalized, idealized profile model for the alteration, mineralization and resistivity distribution of typical porphyry $\mathrm{Cu}$ deposits was summarized [12]. It revealed that electrical resistivity and polarizability features vary significantly with different levels of mineralization and alteration, the essence of which is the difference in the content and connectivity of metal sulfides [13]. This caused electrical (DC) and electromagnetic (EM) soundings to become frequently used ways to image the underground structure of porphyry $\mathrm{Cu}$ deposits [14]. For instance, 3D joint inversion of magnetotelluric sounding (MT) and Z-axis tipper electromagnetic data were used to image intrusive rocks and alteration zones beneath the Morrison porphyry Cu-Au-Mo deposit in British Columbia, Canada [15].

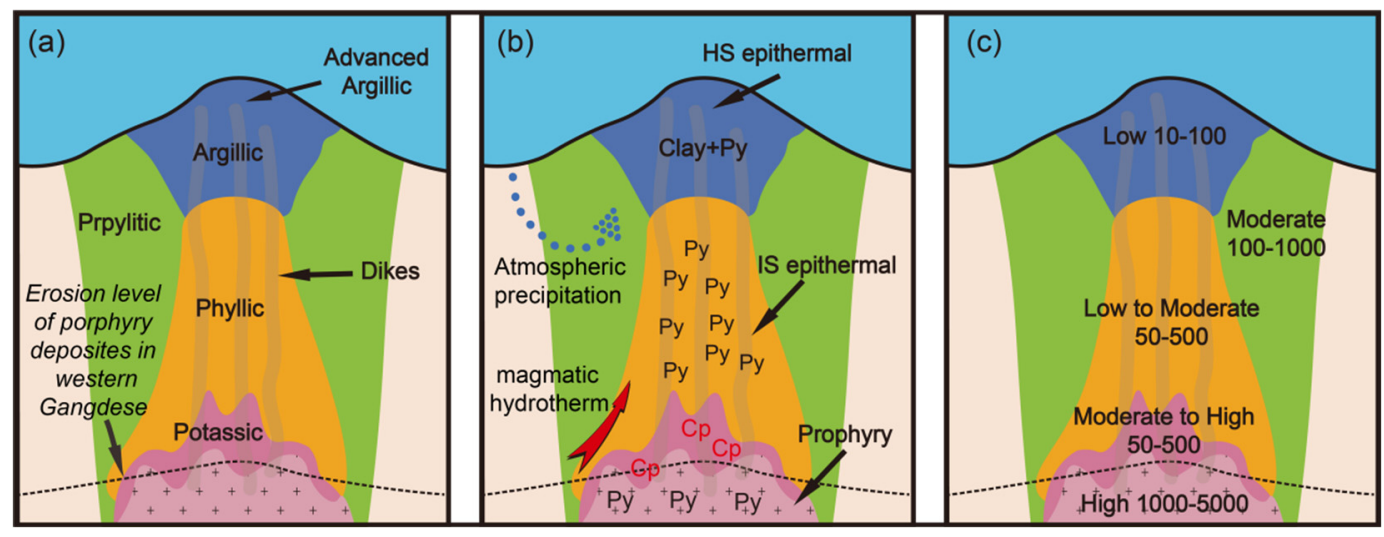

Figure 1. (a) Typical porphyry system alteration pattern; (b) Expected sulfide mineralization; (c) Expected electrical resistivity responses for uneroded and eroded porphyry deposits. Py = pyrite, $\mathrm{Cp}=$ chalcopyrite. Modified from [12,15].

Among these EM methods, audio-frequency magnetotelluric soundings (AMT) are commonly used to study the structure of metallic deposits [16]. AMT uses natural EM signals as the source and, therefore, has an exploration depth of greater than $1 \mathrm{~km}$ and a higher exploration accuracy than broad-band MT works. In addition, AMT is very suitable for exploration in high-elevation mining areas such as the study area in this research. The Cimabanshuo porphyry $\mathrm{Cu}$ deposit in southern Tibet has an average elevation of over $5800 \mathrm{~m}$; therefore, there is no need to deploy long wires and transport a large number of cables, as is the case with DC soundings and the controlled-source audio-frequency magnetotelluric method (CSAMT) [17]. However, the application of the AMT method to such high-elevation areas as Cimabanshuo still has some limitations. Specifically, the AMT method can detect a maximum depth of $\sim 1-3 \mathrm{~km}$. However, the elevation difference between the highest and lowest points is more than $900 \mathrm{~m}$ within a horizontal distance of less than $1 \mathrm{~km}$ in Cimabanshuo area. The influence of topography cannot be ignored [18] According to the forward modelling studies of Dong et al. [19], such clear topographic relief in Cimabanshuo cannot be ignored, otherwise, the reliable underground electrical structure cannot be obtained by inversion [20]. Furthermore, as mentioned above, the porphyry metallogenic system is a complex three-dimensional (3D) system; therefore, a reliable underground structure cannot be obtained by one-dimensional (1D) or two-dimensional 
(2D) inversion algorithms. In summary, for the Cimabanshuo deposit, only 3D inversion considering the effects of topography can reveal reliable underground structures. In this research, we carried out a 3D inversion with topography for an AMT array that was made up of 59 sites collected from the Cimabanshuo deposit, obtaining the underground electrical structure. Combined with other geological information, new constrains on the potential intrusive rocks and alteration zones were provided according to a detailed interpretation.

\section{Geological Settings of the Cimabanshuo Porphyry Copper Deposit}

There are many large-scale and super-large porphyry $\mathrm{Cu} \pm \mathrm{Mo} \pm \mathrm{Au}$ deposits in the Gangdese metallogenic belt, such as the Tinggong, Qulong and Jiama deposits [21,22]. The Cimabanshuo deposit is located in the western section of the Gangdese belt (Figure 2) [23]. Based on the study of Miocene adakites, these Gangdese deposits were suggested to be formed in an extensional tectonic setting after the subduction-collision between the Indian and Eurasian plates [24]. The ages of ore-bearing granodiorite porphyry were approximately $15.2 \pm 0.8 \mathrm{Ma}-15.2 \pm 0.7 \mathrm{Ma}$ (15.2 Ma) when the post-collision (25-13 Ma) extension occurred. The break-up of slab was supposed to lead to the upwelling of mantle-derived magma and its intrusion into the juvenile, thickened, mafic lower-crust, which provided heat for its melting and released abundant $\mathrm{Cu}$ - and sulfide-rich ore-forming fluids [25].
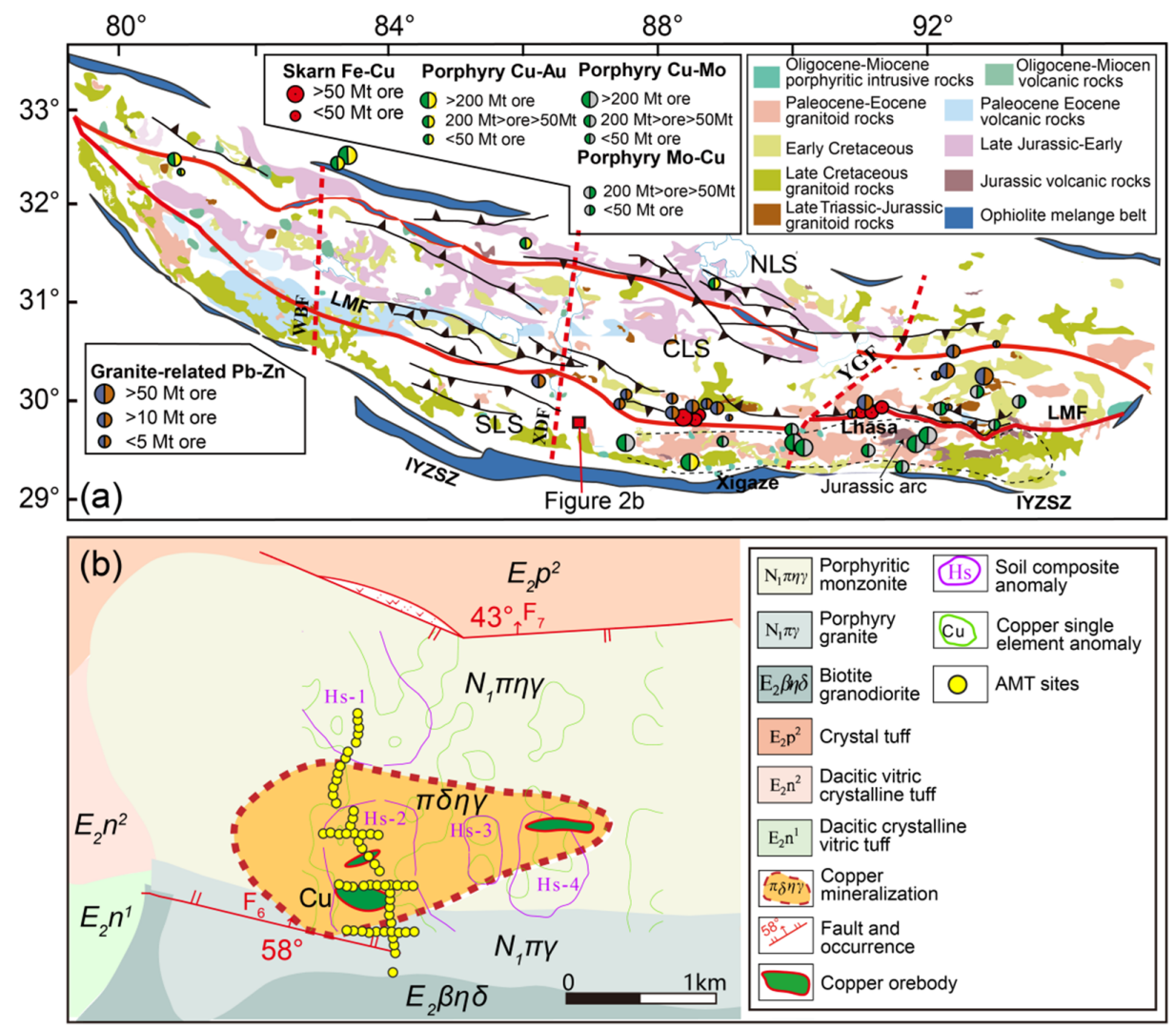

Figure 2. (a) Simplified geologic map of the Gangdese metallogenic belt, showing the distribution of Late Triassic to Miocene magmatic rocks and ore deposits in the belt (modified from [7]); (b) Geological map of the Cimabanshuo porphyry copper deposit and the locations of AMT sites (modified from [23,25]). Abbreviations: CLS = central Lhasa subterrane, IYZSZ = Indus-Yarlung-Tsangpo suture zone, LMF $=$ Luobadui-Milashan fault, NLS $=$ northern Lhasa subterrane, SLS = southern Lhasa subterrane, $\mathrm{WBF}=$ Wenbu Fault, $\mathrm{XDF}=$ Xuru-Dangreyong Fault, YGF = Yadong-Gulu Fault.

Due to its high elevation and remote location, very few exploration works have been executed in Cimabanshuo, including low-degree geological mapping and geochemical studies [23]. Miocene porphyry bodies, NE-trending and EW-trending faults, and well- 
nested geochemistry anomalies and remote sensing hydroxyl anomalies indicated good metallogenic potentials and geological conditions for $\mathrm{Cu}$ and $\mathrm{Pb}$ mineralization. A certain amount of massive and fine-grained pyritization along micro-fractures was found on the ground [25]. Two relatively large-scale and almost EW-trending mineralized alteration zones were delineated. They were $\sim 2 \mathrm{~km}$ in E-W and $\sim 350-1200 \mathrm{~m}$ in S-N direction (Figure 3). The NW- and NE-trending structures are suggested to be closely related to mineralization. Regional structures control the intrusion of magma, hydrothermal alteration and mineralization, which may play an important role in the activation of ore-forming materials, the passage of ore-forming fluids and the space of ore-forming occurrence [26]. Miocene monzogranite porphyry, porphyritic monzogranite and granite porphyry were suggested to closely correlate with porphyry mineralization. The main mineralization types include pyrite, chalcopyrite, molybdenite and malachite [23]. Chalcopyrite is mainly distributed within the rock fractures and K-feldspar phenocrysts of porphyritic granite. Malachite is distributed in the fractured surface of rocks and kaolinized altered rocks in the shape of filmy aggregate. Azurite is distributed in the fractured rock surface in the form of film and dissemination, and it is associated with malachite petrochemistry. The major alteration types contain vein-like, massive propylitic and white phyllic alterations. There are many EW- and SN-trending fine fractures within porphyritic monzonitic granite, especially in the rocks to the west of ore bodies. The $\mathrm{Cu}$ mineralization is closely related to the degree of rock fracturing. In other words, the mineralization would be stronger where more fractures occur [25].

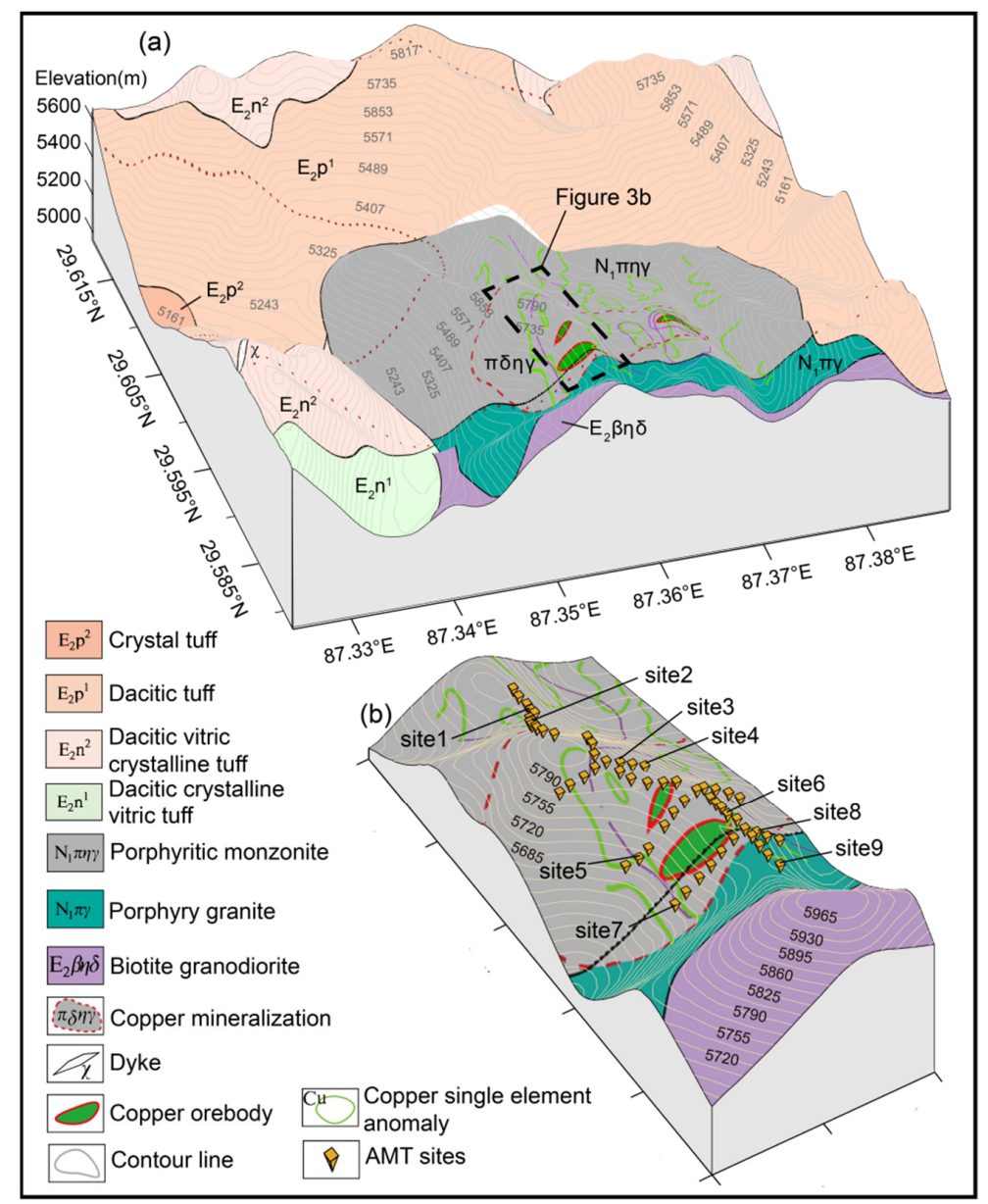

Figure 3. (a) The superposition of geological map and topographic map of the Cimabanshuo deposit with the highest elevation being higher than $5900 \mathrm{~m}$, the lowest elevation reaching nearly $5100 \mathrm{~m}$ and an average value of $\sim 5500 \mathrm{~m}$. (b) Locations of AMT sites of this research. The geological map in Figure $3 a$ is same as Figure $2 b$ and modified from $[23,25]$. 


\section{AMT Data Acquisition and Processing}

The MTU-5A system (developed by Phoenix Geophysics Ltd., Toronto, Canada) was used for AMT data collection and synchronous satellite observation was adopted. In July 2019, 59 sites were deployed to form an array covering the Cimabanshuo $\mathrm{Cu}$ deposit. The array consists of one relatively long NW-SE-trending and three short, almost E-W-trending profiles, which span the entire $\mathrm{Cu}$ mineralization area and pass through two nearly $\mathrm{E}-\mathrm{W}$ strike $\mathrm{Cu}$ ore bodies. The average intra-site distance was $\sim 50 \mathrm{~m}$. The average acquiring time was $2-4 \mathrm{~h}$ for each site in order to obtain the frequency band covering $\sim 10,000 \mathrm{~Hz}$ to $1 \mathrm{~s}$ (Figure 4). The survey area was located in a high-elevation and remote region within the hinterland of Tibet. Therefore, there is almost no sign of human activity and EM noise interference due to the absence of large-scale exploration and mining activities. The time series of AMT were processed by SSMT2000 software developed by the Phoenix Geophysics Ltd., and the reliable impedance tensors were obtained by using a standard Robust algorithm $[27,28]$.
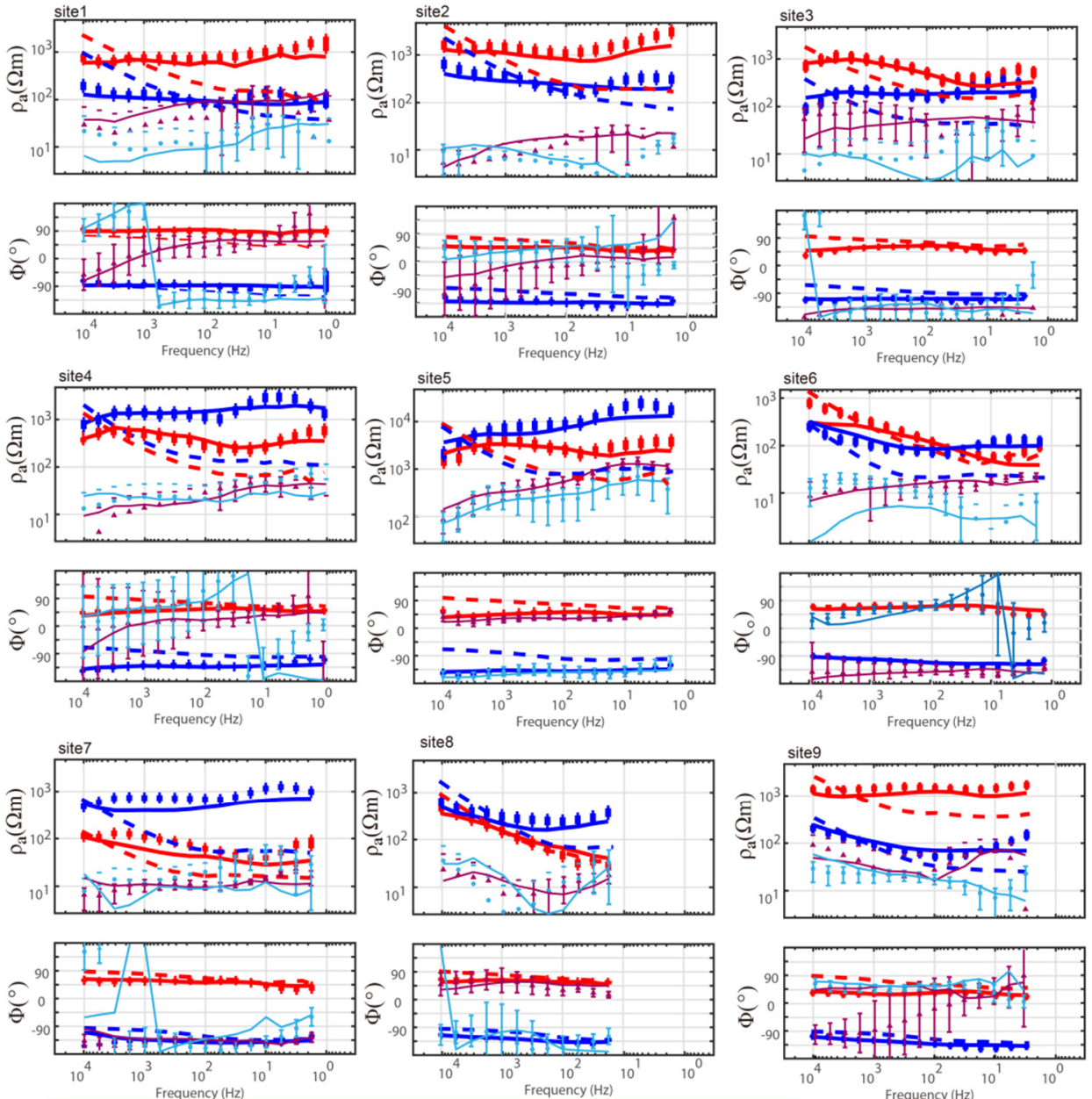

xy mode - $-x y$ mode response curve Ixx mode $-x x$ mode response curve I yx mode - yx mode response curve 1 yy mode —yy mode response curve ---- xy mode response curve without topography -. yx mode response curve without topography

Figure 4. Typical apparent resistivity and phase curves of the research area (scatter), response curves of the 3D inversion model (solid line), and response curves of the 3D inversion model without topography (dashed line). Site1 and Site9 are located in the northern and southern margins of the research area, respectively. Site2-Site4 are located in copper-single-anomaly area. Site5-Site8 are located near the proven copper mineralization zone (Figure 3b). Some data plots for the diagonal components are also shown. 


\section{The Dimensionality and Strike Direction Analysis of AMT Data}

Before inversion and interpretation, a detailed dimensionality analysis should be applied to evaluate the complexity of underground structures and the distortion of AMT data [29]. This research applies two commonly used methods, i.e., the Groom-Bailey (GB) impedance tensor decomposition [30] and phase tensor analysis [31]. According to the theory of skin depth, plotting these indicators by time period can reveal information for different depths (Figure 5) [29]. Generally speaking, the dimensionality and strike direction in the survey area are relatively simple. Specifically, the AMT data of Cimabanshuo array show consistency features only within some local areas, while these subregions differ from each other, for example, Zone1 to the north and Zone2 to the south.
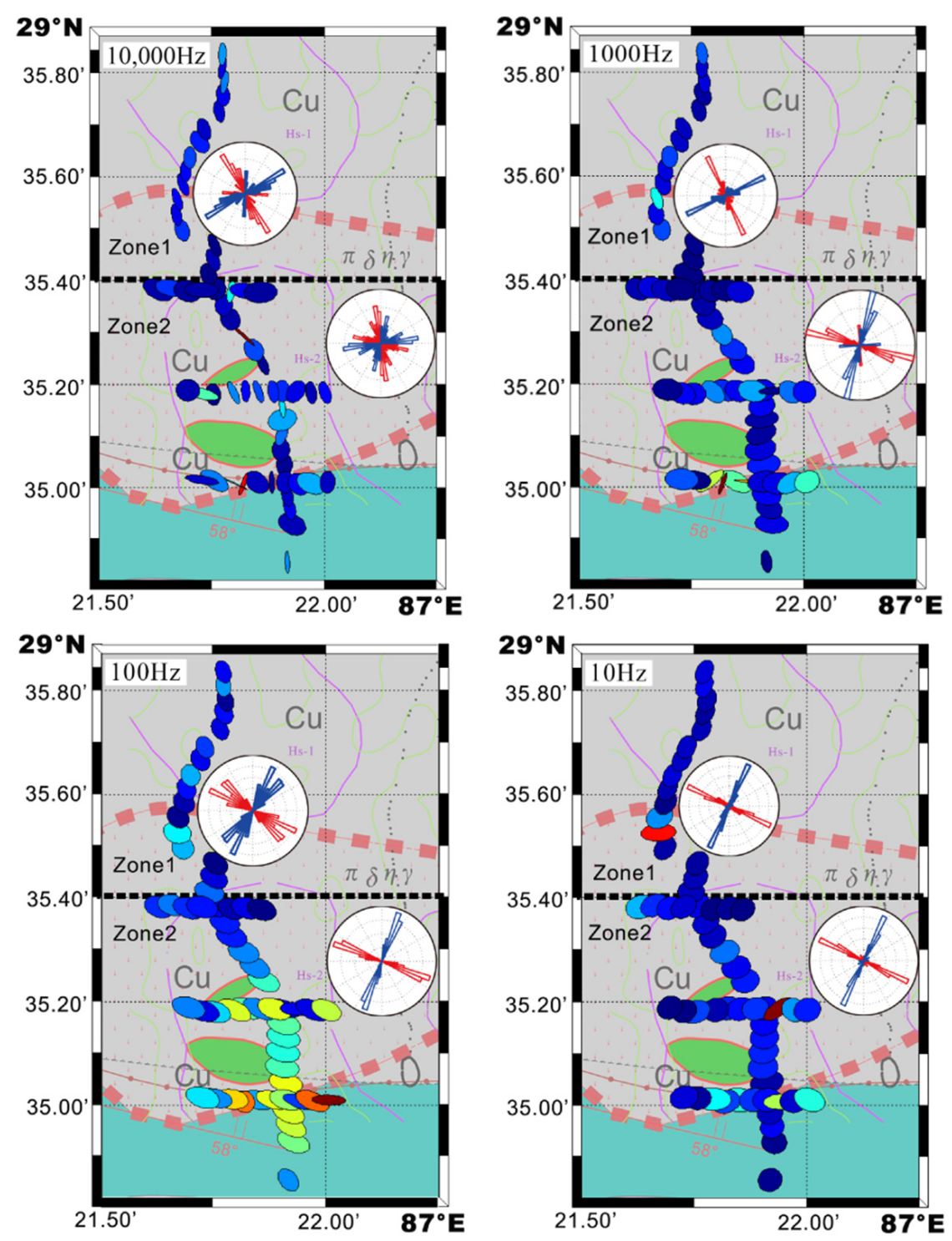

Phase tensor $\beta$ (Skew)

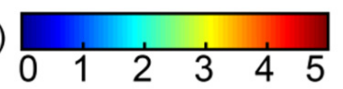

Figure 5. Geoelectric strike direction and dimensionality analysis of the AMT sites by period. The AMT sites are analyzed by two individual groups according to the location of the copper deposits. The red-blue sectors shown on the rose diagrams illustrate the inherent $90^{\circ}$ ambiguity of the results of Groom-Baily decomposition [30]. The phase tensors [31] are represented by colored ellipses filled according to skew ( $\beta$ angle) values. 
The phase tensors of Zone1 show overall small skew $(\beta)$ values from high to low frequencies $(10,000-10 \mathrm{~Hz})$, most of which are less than $2^{\circ}$, indicating simply $1 \mathrm{D} / 2 \mathrm{D}$ structures. The electrical strike directions obtained from the GB decomposition are also relatively simple. Their $90^{\circ}$ inherent ambiguity could be eliminated according to geological strikes. The direction of $10,000-1000 \mathrm{~Hz}$ is $\sim \mathrm{N} 60^{\circ} \mathrm{E}$, which may reflect the trends of some shallow faults. By contrast, the direction of $100-10 \mathrm{~Hz}$ is mainly $\sim \mathrm{N} 120^{\circ} \mathrm{E}$, which is similar to the boundary of the $\mathrm{Cu}$ mineralization belt and likely caused by underground lithologic interfaces.

The phase tensors of Zone2 show totally different features. Especially, those of $100 \mathrm{~Hz}$ show very large $\beta$ angles (mostly greater than $3^{\circ}$ ) and complex long-axis directions, compared with their northern counterparts within Zone1. This can also be verified by the relatively complicated strike directions derived from GB decomposition. Considering that Zone 2 covers the mineralization area and proven ore bodies. Additionally, as mentioned above, the porphyry metallogenic system is a complex $3 \mathrm{D}$ system. Therefore, it is reasonable to determine a relatively $3 \mathrm{D}$ electrical structure beneath Zone2.

It is notable that the strike directions of the highest frequencies $(10,000 \mathrm{~Hz}$ and $1000 \mathrm{~Hz})$ are also clearly aligned with the topographic ridge that the survey ran along. The interface between the topographic ridge and air is the most significant electrical resistivity contrast, which can make prominent 2D features. Additionally, the lithologic boundaries are mostly parallel or perpendicular to the extensional direction of the ridge. Therefore, whether the 2D features and clear strike directions are caused by underground structures or topography cannot be determined.

In conclusion, although the electrical dimensionality features in Cimabanshuo are relatively simple and most of the sub-regions are dominated by 1D/2D characteristics, the electrical strikes differ among different sub-regions and depths. In addition, relatively complicated 3D characteristics occur beneath the southern part of AMT array, due to the presence of ore-forming porphyry. In summary, it is necessary to carry out a 3D inversion of AMT data with topography to obtain reliable underground electrical structures beneath Cimabanshuo.

\section{Three-Dimensional Inversion with Topography of AMT Data}

The 3D inversion code of AMT data with topography we used is ModEM, which is based on the Non-Linear Conjugate Gradient (NLCG) algorithm [32,33]. We used Dong Hao's code to generate the initial file and present the inversion results(The link of the code can be found in Supplementary Materials). Then, we import the diagonal (Zxx and Zyy) and non-diagonal (Zxy and Zyx) components of unrotated impedance tensor from 59 sites into the inversion code. After considering the mismatch of different values $(5 \%$ and $10 \%$, etc.) and the weight between model roughness, an error margin of $7.5 \%$ is finally selected. The initial model is a half space with a resistivity of $100 \Omega \mathrm{m}$ and a grid size of $105(\mathrm{Nx}) \times 49(\mathrm{Ny}) \times 60(\mathrm{Nz}) \mathrm{m}$. The horizontal width of the grid is $20 \mathrm{~m}$. Six units are filled in the periphery of the sites, and the width increases by 1.5 times. In the vertical direction, there are 60 layers, including 45 layers of terrain (each layer is $10 \mathrm{~m}$ thick) and the coefficient below the 45 layers increases exponentially by 1.45 times. Because the topography was taken into account, the initial model was constructed with real terrain data. The resistivity of $10^{10} \Omega \mathrm{m}$ was used to represent the air, while the resistivity of $100 \Omega \mathrm{m}$ was used below the surface to represent the earth. Additionally, " 0 " was set in the model covariance file $\left({ }^{*}\right.$.cov file) to lock the air value in the model so that it did not participate in the inversion calculation. In the data file $\left({ }^{*}\right.$.dat file), the $\mathrm{z}$-coordinates of each site were also modified for the relative height of reference points based on the actual terrain data. We chose the data origin as the highest point in the model so that all data sites had non-negative z-coordinates. This ensured the avoidance of sites that were actually embedded inside the Earth, or in the air, which would cause an inaccuracy in the inversion.

We used a tower-type sever (Dell PowerEdge T440) with two processers containing 40 cores and 84 GB memories for the Parallel inversion calculation. The average time 
required for each iteration was about $1.75 \mathrm{~h}$. After 66 iterations, the final overall NormalizedRoot-Mean-Square error (nRMSe) for all sites was 1.77. The fitting of observed data was mostly acceptable, and those of several measured sites are shown in Figure 4.

The nRMSe values for every site are shown in Figure 6. Additionally, the frequency histogram of the nRMSe for all sites demonstrates that most sites ( 49) had low nRMSe values between 0 and 2.5, indicating an acceptable fitting of the observed data.
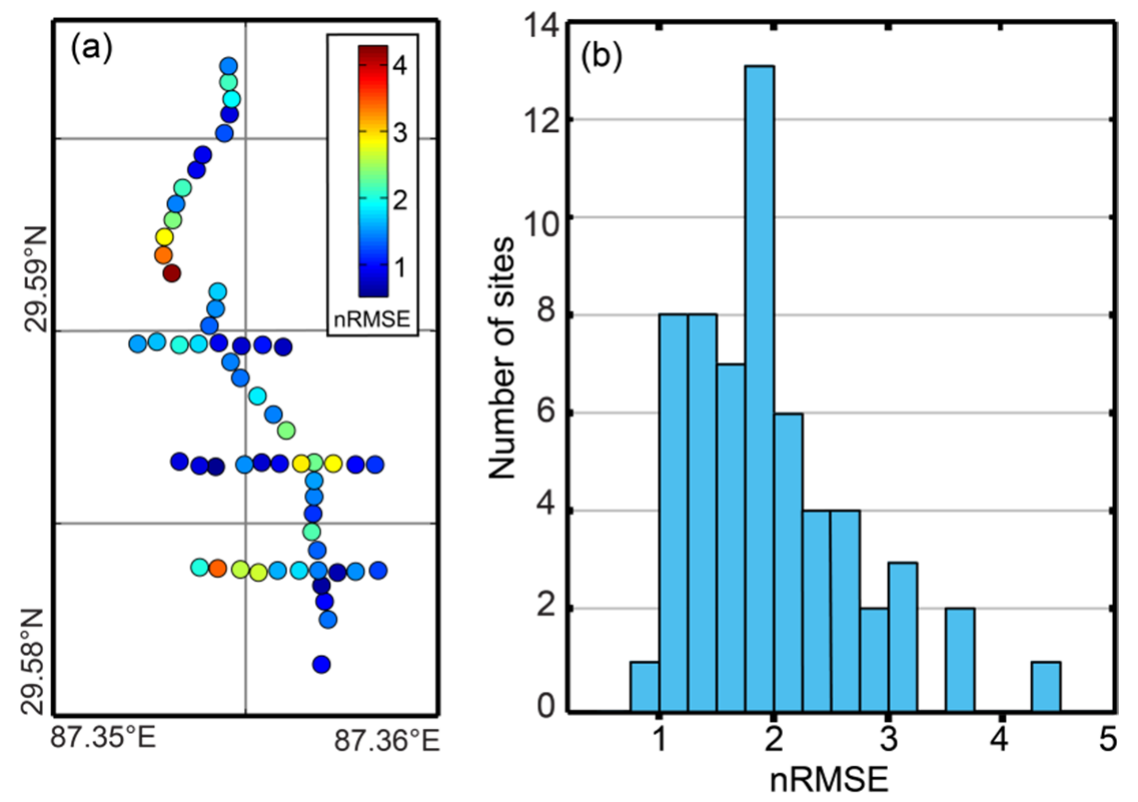

Figure 6. (a) Horizontal distribution of model misfits (nRMSE) of the 3D inversion with topography model for each AMT site. (b) Frequency histogram of site-by-site nRMSE.

However, it is notable that the data of several sites in Figure 4 do not seem to be well fitted, which could be due to the staircasing of the topography in the model, since the ModEM code uses finite-difference algorithm when conducting the forward modelling. The topography cannot be perfectly created by regular cube grids. Therefore, one option was to test multiple inversions using different parameter settings and select the bestfitted inversion for interpretation. In order to confirm the necessity of the inversion with topography, we also removed the topography of the inversion model by replacing the air $\left(10^{10} \Omega \mathrm{m}\right)$ with $100 \Omega \mathrm{m}$. The responses of the revised model are also shown in Figure 4 by dash lines. Clearly, the fittings became worse, compared with the original inversion model with topography, and the total R.M.S. misfit also increased to 3.0. Therefore, we suggested that an inversion that included topography was necessary.

The final 3D inversion model, which included the topography, was demonstrated by two different methods: horizontal slice (Figure 7), and vertical slice (Figure 8), on which we carried out a detailed geological interpretation. 
(a)
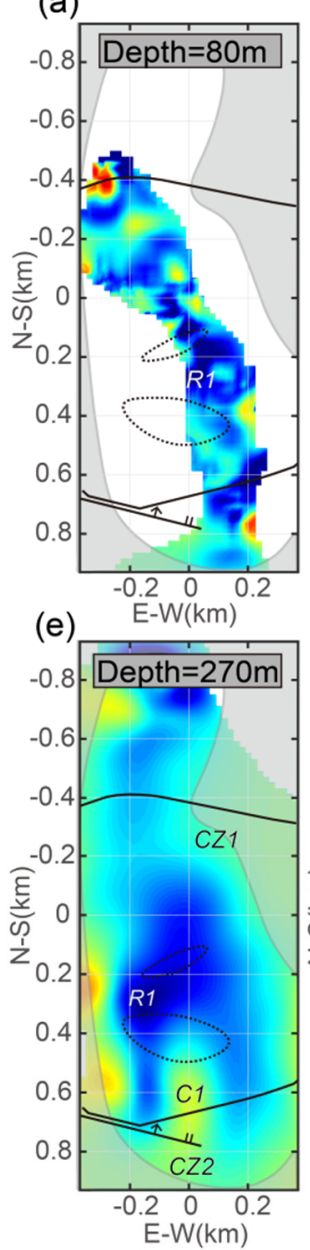

(b)
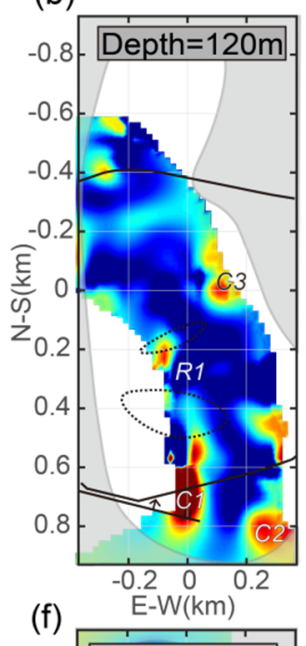

(c)
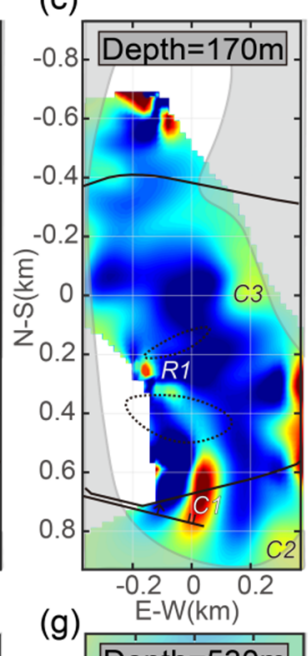

(d)
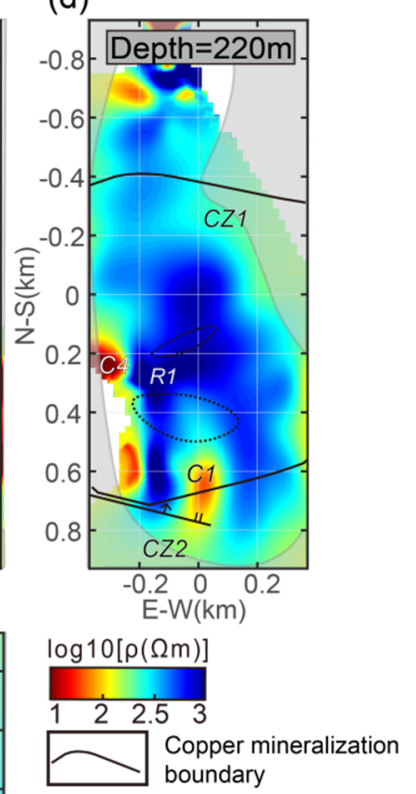

boundary

$\because \cdots$ Copper orebody

एर Fault

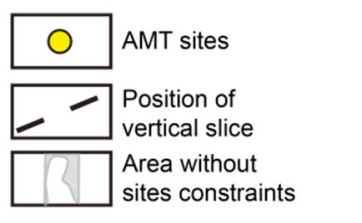

Figure 7. Horizontal slices of 3D inversion model at depths of 80, 120, 170, 220, 270, 320, $530 \mathrm{~m}$ $(\mathbf{a}-\mathbf{g})$, respectively. The pure white regions represent air at corresponding depths. The superposed geological features are the same as Figure $3 \mathrm{~b}$. Warm and cold colors indicate low and high resistivity, respectively. CZ1 and CZ2 indicate major conductive zones.

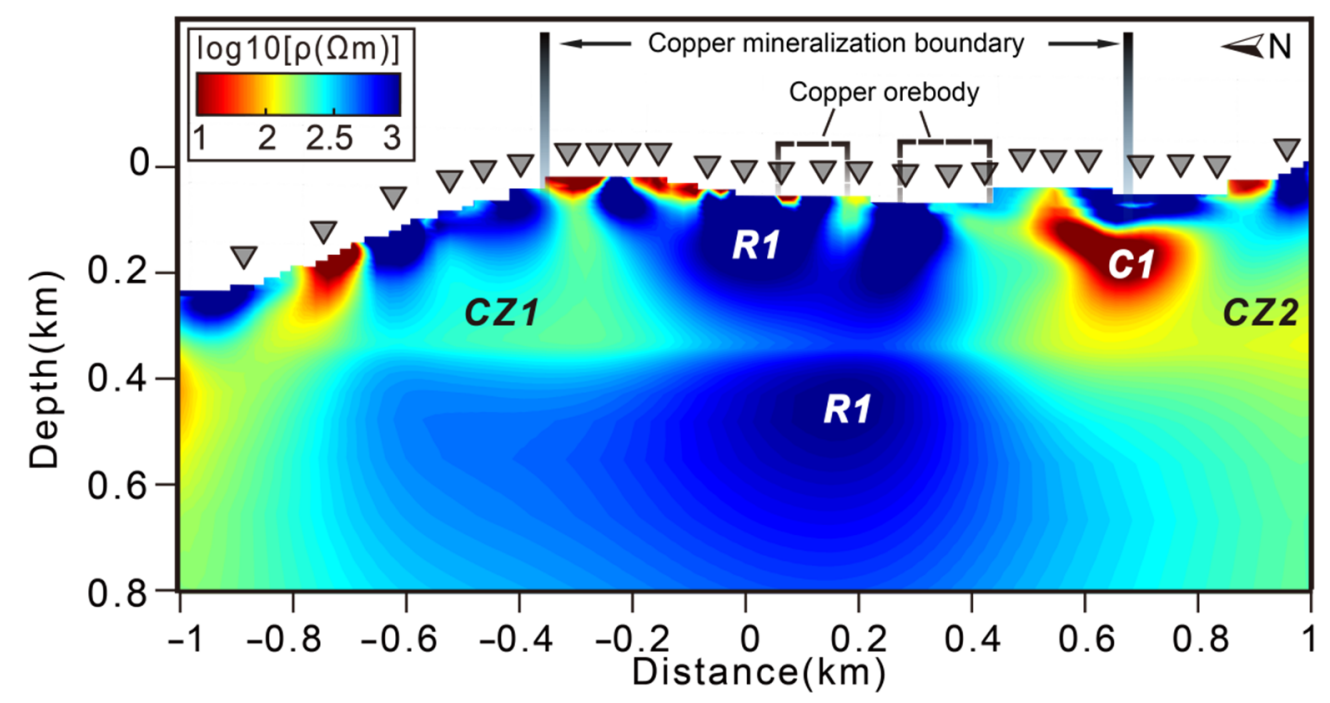

Figure 8. The NW-SE trending vertical slice of the 3D inversion model along the transects shown in Figure $7 \mathrm{~g}$. CZ1 and $\mathrm{CZ2}$ are conductive zones. $\mathrm{R} 1$ is high-resistivity zone. $\mathrm{C} 1$ is a significant conductor. 
In Figure 8, C1 is a clear and significant anomaly; therefore, sensitivity tests were performed on it. We replaced $\mathrm{C} 1$ by resistive material and carried out a forward modelling; the result is shown in Figure 9. It was evident that the degree of fitting decreased, which indicated the moderate presence of $\mathrm{C} 1$.
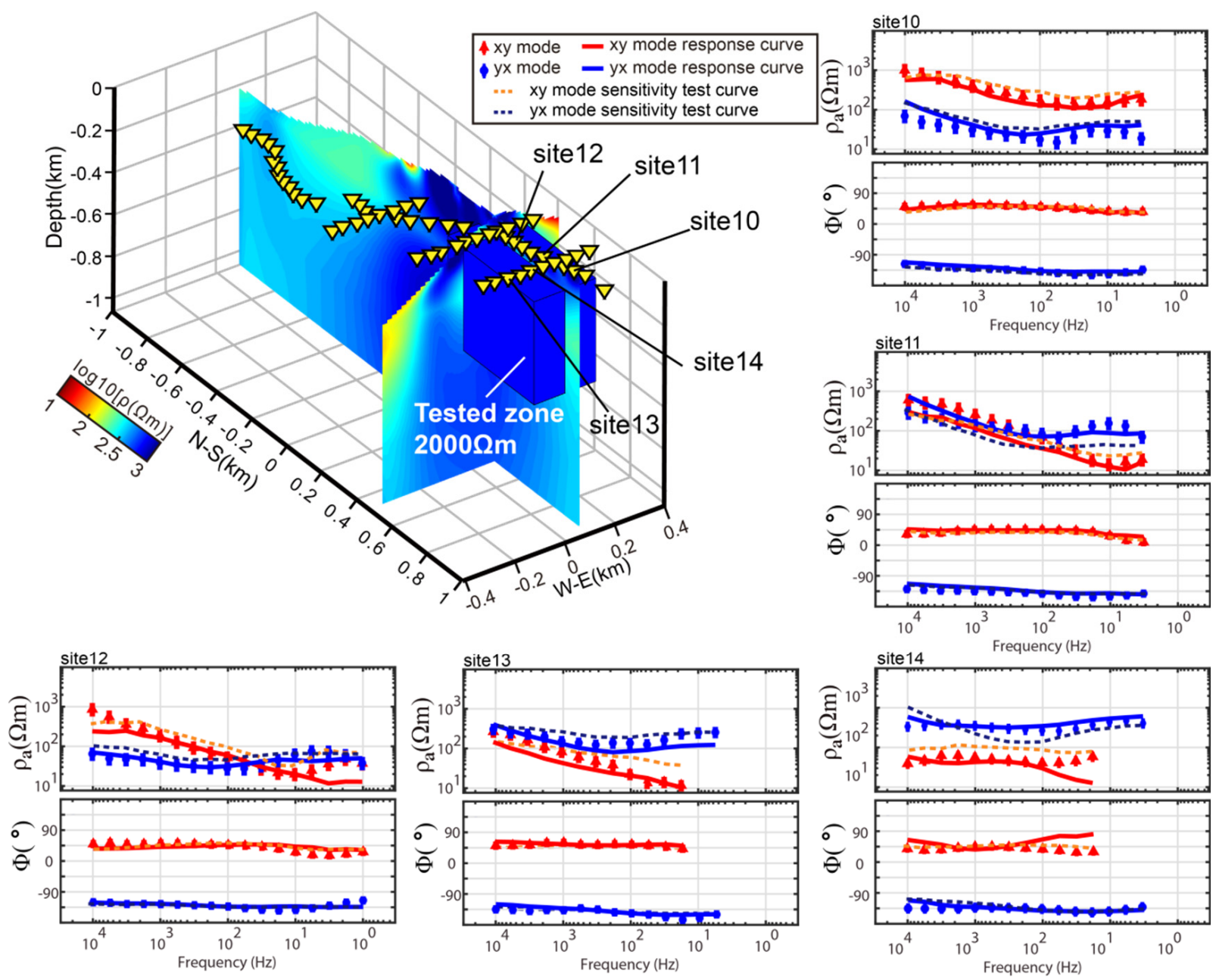

Figure 9. Sensitivity tests for foliate alteration and C1 (Figure 8). The existence of a high conductor is plausible by comparing response of the model before and after the tests.

\section{Geological Interpretations of the Electrical Resistivity Models}

The expected electrical resistivity responses of typical porphyry systems vary depending on alteration degrees and different types of deposits (Figure 1, modified from [12]). The alteration zones are formed under specific temperature and salinity conditions; therefore, the space and depth of each alteration zone differ significantly for different deposits. Accordingly, we made geological interpretations of the inversion model for the Cimabanshuo deposit; the 3D resistivity model with topography is shown in Figure 10. 


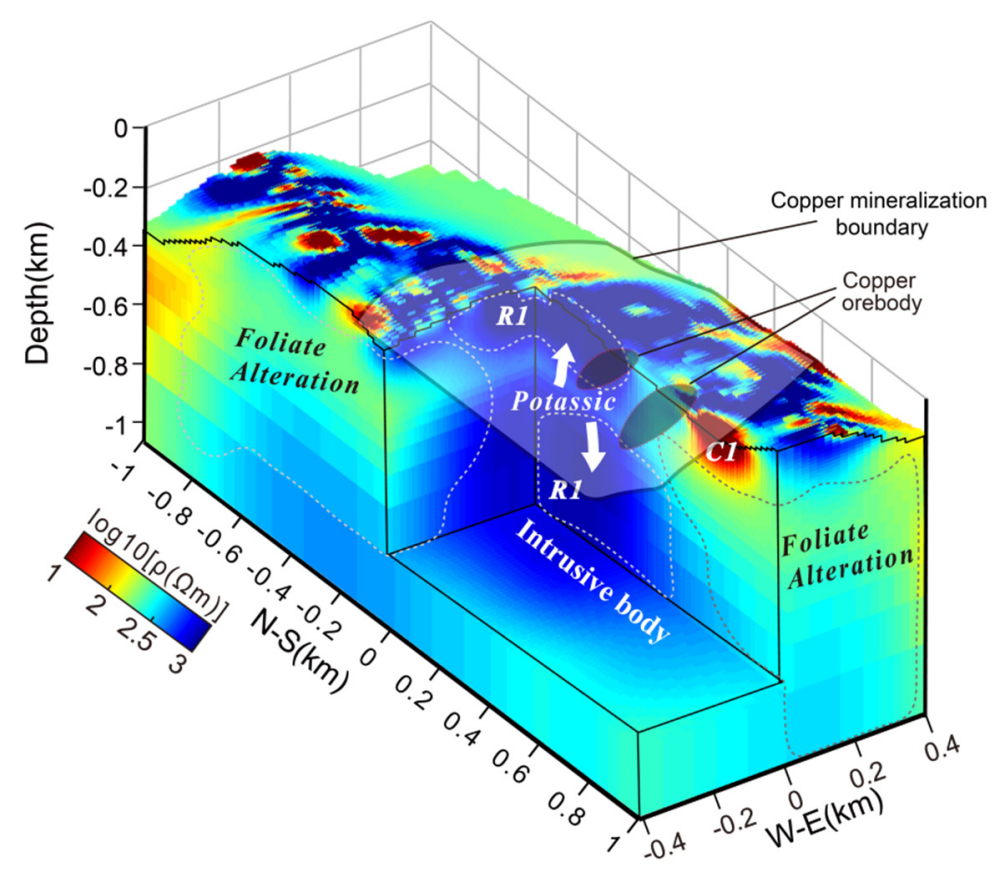

Figure 10. Perspective display of the 3D resistivity model with topography and schematic geological interpretation. R1 is high-resistivity potassic zone.

\subsection{High-Resistivity Potassic Intrusive Rocks}

A wide range of the high-resistivity zone, R1, occurs beneath the research area, which can be observed in both horizontal and vertical sections (Figures 7 and 8). This is not unexpected. If a deposit is altered to porphyry level, according to the idealized electrical resistivity profile of porphyry system shown in Figure 1 (modified from [12]), the highresistivity potassic zone dominates the resistivity profile. Potassic zones are composed of crystalline intrusive rocks and usually show high-resistivity features due to the current flow being limited by the absence of micropores within rocks [10]. The resistivity of the newly formed intrusive rocks is generally $1000-5000 \Omega \mathrm{m}$, which varies with the fracturing degree. There is a large area of $15.2 \pm 0.8 \mathrm{Ma}-15.2 \pm 0.7 \mathrm{Ma}(\sim 15.2 \mathrm{Ma})$-aged Gangdese ore-bearing granitic porphyry outcrop in Cimabanshuo area [23]. However, it can be observed that the resistivity range of $\mathrm{R} 1$ is $\sim 500-2000 \Omega \mathrm{m}$, which is clearly lower than newly formed intrusive rock.

In fact, the locations of $\mathrm{Cu}$ mineralization delineated by geological mapping are also mainly located in the high-resistivity area (Figure 7). This abnormal observation is actually similar to that of the Morrison porphyry $\mathrm{Cu}$ deposit at the Cordillera Mountains, Canada [15]. The resistivity values beneath the $0.3 \% \mathrm{Cu}$ belt predominantly range from 100 to $1000 \Omega \mathrm{m}$, which was suggested to contain potassic intrusive rocks with low-content or/and disconnected metal sulfides. The average grade of $\mathrm{Cu}$ ore in Cimabanshuo is $\sim 0.2629-0.5726 \%$ [23], which is essentially the same as that of Morrison $(\sim 0.3 \%$, [15]). According to the idealized model in Figure 1, the most likely explanation for the highresistivity body nearest to the $\mathrm{Cu}$ ore body is the potassic intrusive rocks. At the final stage of porphyry mineralization, the metallic elements precipitate in the form of metal sulfides, and then cool down and react with the surrounding rocks. Consequently, chalcopyrite and molybdenite precipitate, present in quartz veins and disseminated in potassic altered rocks, generates $\mathrm{Cu}, \mathrm{Fe}$, and $\mathrm{Mo}$ sulfides with potentially economical values [4]. The Cimabanshuo chalcopyrite is diffusedly distributed along the rock fractures and K-feldspar phenocrysts of porphyry granites [25]. However, the abundance of sulfide in the potassic rocks is not high (usually only $\sim 1-2 \mathrm{vol} \%$ ), the interconnection of which is usually poor [13]. Therefore, the resistivity values are usually higher than $1000 \Omega \mathrm{m}$. In conclusion, it is 
plausible to interpret the medium-high resistivity blocks near the $\mathrm{Cu}$ ore body as potassic intrusive rocks.

\subsection{High-Conductivity or Sulfide-Rich Foliate Alteration Zone}

In the upper part of inversion model (Figures 7 and 8), there are several significantly conductors that are shallower than $200 \mathrm{~m}$, such as C1, C2 and C3. Their resistivity values are all less than $100 \Omega \mathrm{m}$, even less than $5 \Omega \mathrm{m}$, such as $\mathrm{C} 1$; its rational existence is verified in Figure 9. According to the idealized resistivity profile in Figure 1, there are several possible explanations for this kind of high conductors, which are discussed one-by-one according to the geological information of the Cimabanshuo deposit as follows.

\subsubsection{Argillic Alteration Zone}

The porphyry deposits with a shallow argillation and late-stage argillation alteration can show an extremely low resistivity at near-surface depths due to the clay minerals within the argillaceous zone [3]. Clay minerals are usually loose and have a large porosity, resulting in the enrichment of secondary high-conductivity materials, such as saline fluids, which greatly reduce bulk resistivity [34]. However, we do not suggest that the above conductors are caused by the argillaceous alterations. The reason is that most of argillaceous alteration occurs under the condition of low-degree denudation. Under this condition, according to the idealized porphyry metallogenic model (Figure 1a), the hydrothermal Ag- $\mathrm{Pb}-\mathrm{Zn}$ metallogenic system has not been entirely denuded, and thus the underlying porphyry metallogenic system cannot be well exposed [35]. In this case, the above conclusion that the high-resistivity blocks are porphyry would be invalid. In fact, according to the fission-track dating and thermal simulation/modeling of the Zhunuo porphyry $\mathrm{Cu}$ deposit $10 \mathrm{~km}$ far to northwest of Cimabanshuo deposit, the main deposits of the western Gangdese belt experienced at least two rapid uplifts, i.e., 8-11 Ma and 4-6 Ma after the main metallogenic period ( 15.2 Ma, [36]). The denudation amount of Zhunuo deposit was suggested to be 2.25-2.63 km [37]. Cimabanshuo has a higher elevation than Zhunuo deposit (averagely $\sim 4600 \mathrm{~m}$ ). Thus, it might experience a larger degree of denudation. Under this condition, the shallow hydrothermal Ag-Pb-Zn metallogenic system and the argillaceous alteration zone are unlikely to be preserved [3], and thus the possibility of interpreting the shallow conductors as argillaceous alteration zones for Cimabanshuo could be ruled out.

\subsubsection{Massive Sulfide}

Except the argillation excluded above, another possible mechanism for the conductors surrounding the high-resistivity intrusive rocks might be rich in metal sulfides. Nelson [13] collected 109 sets of resistivity measurements from four porphyry $\mathrm{Cu}$ deposits, and the results showed that the resistivity was inversely proportional to the sulfide content, although this study did not include massive sulfide samples. However, other studies showed that the sulfides generally weighed more than $50 \mathrm{wt} . \%$ and interconnected easily, with an extremely low resistivity (up to $\sim 0.1-1 \Omega \mathrm{m}$, [38]). In fact, most of the apparent conductors in our resistivity model cannot reach such low resistivity values. Instead, most of them range from 10 to $30 \Omega \mathrm{m}$. Additionally, there is no evidence of massive $\mathrm{Cu}$ sulfide from drilling work in Cimabanshuo, and the porphyry $\mathrm{Cu}$ content here is not very high, with a maximum of $0.5726 \%$ [23]. Therefore, this possibility can also be essentially ruled out.

\subsubsection{Foliate Alteration Zone}

In a porphyry metallogenic system, except for the argillization and massive sulfide excluded above, disseminated sulfides can also reduce whole-rock resistivity. However, this mechanism cannot reduce as drastically as the former two, considering that the significant conductors, $\mathrm{C} 1, \mathrm{C} 2$, and $\mathrm{C} 3$, are mainly distributed around the inferred $\mathrm{Cu}$ ore body. According to the theory of porphyry mineralization [2], the ore-forming fluids become increasingly acidic when they rise to the near-surface and cool down, which leads to leaflike (quartz-sericite-pyrite) alterations [4]. According to the idealized resistivity model 
of the porphyry deposit in Figure 1, the alteration closest to the ore body is dominated by sericitization. The kind of alteration is characterized by a large amount of veinlet disseminated Pyrite (up to $20 \mathrm{vol} \%$ ), which can significantly lower the whole-rock resistivity. This mainly depends on the number and connectivity of sulfide particles [13]. When the sulfide content is $3-20 \mathrm{wt} . \%$, it is distributed in veins. The corresponding whole-rock resistivity can range between 100 and $1000 \Omega \mathrm{m}$. When the sulfide content reaches $20 \mathrm{wt} . \%$, the connectivity is relatively improved, and the whole-rock resistivity can be reduced to $10 \Omega \mathrm{m}$. The alteration found in the Cimabanshuo deposit is mainly a vein-type block propylitization and white-color sericitization alteration [23]. The conductors around the ore body are mostly 10-300 $\Omega \mathrm{m}$, which are inferred to contain sulfide with a relatively high content or good connectivity. Combined with the location of the high conductors and the actual geological conditions, we suggest that they may represent sericitization alteration containing pyritization. The medium-high conductor $(\sim 50-300 \Omega \mathrm{m})$ around the inferred intrusive rocks of Morrison porphyry $\mathrm{Cu}$ deposit in Canada [15], is also interpretated in this way, which can be compared to that of Cimabanshuo. In fact, the proven ore bodies of Cimabanshuo are mainly located at the junction zones of high-resistivity intrusive rocks and relatively high-conductivity sericitization alteration zones, which could also be favorable positions for mineralization.

\section{Conclusions}

We conducted a 3D inversion with topography for 59 AMT sites belonging to an array covering the main mineralization zone and ore bodies of Cimabanshuo Cu porphyry deposit in the western Gangdese metallogenic belt, Tibet. Combined with other geological information, the main following conclusions can be drawn as follows:

(1) A large range of high-resistivity anomaly $(\sim 500-2000 \Omega \mathrm{m})$ appears beneath the proven $\mathrm{Cu}$ mineralization zone and ore bodies, and is interpreted as intrusive rock with potassic alterations. Although containing chalcopyrite, it is characterized by middlehigh resistivity due to low sulfide content and poor connectivity.

(2) A series of scattered conductors $(\sim 10-300 \Omega \mathrm{m})$ around the $\mathrm{Cu}$ ore bodies are distributed in the shallow layer from near-surface area to $\sim 200 \mathrm{~m}$, possibly indicating a phyllic alteration containing pyritization and connected metal sulfides.

(3) The proven ore bodies of Cimabanshuo are mainly located at the junction regions of high-resistivity intrusive rocks and relatively high-conductivity sericitization alteration zones.

In summary, the 3D inversion with topography of AMT data can visually display the 3D distribution of intrusive rocks and alteration zones beneath porphyry Cu deposits in high-elevation regions, and provide a reference for further exploration works.

Supplementary Materials: The following supporting information can be downloaded at: www. mdpi.com/xxx/s1, Figure S1: title; Table S1: title; Video S1: title. The supplementary materials contain the model and data files of 3D inversion.

Author Contributions: Conceptualization, P.Q. and Y.Y.; methodology, Y.Y.; software, H.D. and P.Q.; validation, P.Q., L.X., J.H.; formal analysis, S.J. and W.W.; investigation, L.X.; resources, Y.Y.; data curation, Y.Y.; writing—original draft preparation, P.Q. and Y.Y.; writing—review and editing, P.Q. and Y.Y.; project administration, Y.Y. All authors have read and agreed to the published version of the manuscript.

Funding: This research was mainly supported by the National Key Research and Development Program of China (NO. 2018YFC0604104). The development of some methods used in this research was supported by National Natural Science Foundation of China (Grant NO. 41974092 and 41704079), Fundamental Research Funds for the Central Universities (NO. 2652018271).

Data Availability Statement: The model and data files of 3D inversion were compressed and uploaded as supplementary files. 
Acknowledgments: We thank Gary Egbert and his group members for sharing their 3D inversion code. We thank Alan Jones and Gary NcNeice for using their tensor decomposition codes. We thank all the faculty and graduate students from the MT group in China University of Geosciences (Beijing) for providing facilities for data collection and processing.

Conflicts of Interest: The authors declare no conflict of interest.

\section{References}

1. Kesler, S.E.; Wilkinson, B.H. Earth's copper resources estimated from tectonic diffusion of porphyry copper deposits. Geology 2008, 36, 255-258. [CrossRef]

2. Richards, J.P. Postsubduction porphyry $\mathrm{Cu}-\mathrm{Au}$ and epithermal Au deposits: Products of remelting of subduction-modified lithosphere. Geology 2009, 37, 247-250. [CrossRef]

3. Sillitoe, R.H. A Plate Tectonic Model for the Origin of Porphyry Copper Deposits. Econ. Geol. 1972, 67, 184-197. [CrossRef]

4. Richards, J.P. Tectono-Magmatic Precursors for Porphyry Cu-(Mo-Au) Deposit Formation. Econ. Geol. 2003, 98, 1515-1533. [CrossRef]

5. Sillitoe, R.H.; McKee, E.H. Age of supergene oxidation and enrichment in the Chilean porphyry copper province. Econ. Geol. 1996, 91, 164-179. [CrossRef]

6. Mathur, R.; Ruiz, J.; Munizaga, F. Relationship between copper tonnage of Chilean base-metal porphyry deposits and Os isotope ratios. Geology 2000, 28, 555-558. [CrossRef]

7. Hou, Z.Q.; Meng, X.J.; Qu, X.M.; Gao, Y.F. Copperore potential of adakitic intrusives in Gangdese porphyry copper belt: Constrains from rock phase and deep melting process. Miner. Depos. 2005, 24, 121-132.

8. Lowder, G.G.; Dow, J.A.S. Geology and exploration of porphyry copper deposits in North Sulawesi, Indonesia. Econ. Geol. 1978, 73, 628-644. [CrossRef]

9. Pinet, N.; Gloaguen, E.; Giroux, B. Introduction to the special issue on geophysics applied to mineral exploration. Can. J. Earth Sci. 2019, 56, 5-8. [CrossRef]

10. Lowell, J.D.; Guilbert, J.M. Lateral and vertical alteration-mineralization zoning in porphyry ore deposits. Econ. Geol. 1970, 65, 373-408. [CrossRef]

11. Mitchinson, D.E.; Enkin, R.J.; Hart CJ, R. Linking Porphyry Deposit Geology to Geophysics via Physical Properties: Adding Value to Geoscience BC Geophysical Data; Geoscience BC: Vancouver, BC, Canada, 2013.

12. Hübert, J.; Lee, B.M.; Liu, L.; Unsworth, M.J.; Richards, J.P.; Abbassi, B.; Cheng, L.Z.; Oldenburg, D.W.; Legault, J.M.; Rebagliati, M. Three-dimensional imaging of a Ag-Au-rich epithermal system in British Columbia, Canada, using airborne z-axis tipper electromagnetic and ground-based magnetotelluric data. Geophysics 2015, 81, B1-B12. [CrossRef]

13. Nelson, P.H. Estimation of sulfide content from induced polarization data. Geophysics 1983, 48, 62. [CrossRef]

14. Meju, M. Geoelectromagnetic Exploration for Natural Resources: Models, Case Studies and Challenges. Surv. Geophys. 2002, 23, 133-206. [CrossRef]

15. Lee, B.M.; Unsworth, M.J.; Hübert, J.; Richards, J.P.; Legault, J.M. 3D joint inversion of magnetotelluric and airborne tipper data: A case study from the Morrison porphyry $\mathrm{Cu}-\mathrm{Au}-\mathrm{Mo}$ deposit, British Columbia, Canada. Geophys. Prospect. 2018, 66, $397-421$. [CrossRef]

16. Strangway, D.W.; Swift, C.M.; Holmer, R.C. The application of audio-frequency magnetotellurics (AMT) to mineral exploration. Geophysics 1973, 38, 1159-1175. [CrossRef]

17. Sandberg, S.K. Controlled-source audiomagnetotellurics in geothermal exploration. Geophysics 1982, 47, 100. [CrossRef]

18. Johannes, S.K.; Alexander, V.G.; Alexey, V.K. Topographic distortions of magnetotelluric transfer functions: A high-resolution 3-D modelling study using real elevation data. Geophys. J. Int. 2018, 215, 1943-1961.

19. Dong, H.; Wei, W.B.; Ye, G.F.; Jin, S.; Jing, J.E. Study of Three-dimensional magnetotelluric inversion including surface topography based on Finite-difference method. Chin. J. Geophys. 2014, 57, 939-952.

20. Li, S.H.; Booker, J.R.; Aprea, C. Inversion of magnetotelluric data in the presence of strong bathymetry/topography. Geophys. Prospect. 2008, 56, 259-268. [CrossRef]

21. Wang, R.; Richards, J.P.; Zhou, L.M.; Hou, Z.Q.; Stern, R.A.; Creaser, R.A.; Zhu, J.J. The role of Indian and Tibetan lithosphere in spatial distribution of Cenozoic magmatism and porphyry Cu-Mo deposits in the Gangdese belt, southern Tibet. Earth Sci. Rev. 2015, 150, 68-94. [CrossRef]

22. Hou, Z.Q.; Zhang, H.R. Geodynamics and metallogeny of the eastern Tethyan metallogenic domain. Ore Geol. Rev. 2015, 70, 346-384. [CrossRef]

23. Zhao, Y.Y.; Liu, X.F.; Liu, Y.C.; Liu, B.; Fu, H.L.; Lv, J.L.; Zheng, C.Y. Copper metallogenic condition of Cimabanshuo area around Zhunuo copper mine in Tibet. Gansu Geol. 2017, 26, 28-36.

24. Sun, X.; Hollings, P.; Lu, Y.-J. Geology and origin of the Zhunuo porphyry copper deposit, Gangdese belt, southern Tibet. Miner. Depos. 2021, 56, 457-480. [CrossRef]

25. Zhao, Y.Y.; Liu, X.F.; Liu, Y.C.; Ci, Q.; Xiao, L.B.; Li, L.; Zhang, X.Q. Zircon U-Pb Ages and Geochemical Characteristics of Youqiumi Porphyry Pluton in Cimabanshuo Area, Tibet. Earth Sci. 2018, 43, 4551-4565. 
26. Huang, H.X.; Liu, H.; Li, G.M.; Zhang, L.K.; Cao, H.; Zhou, Q.; Wang, X.X.; Yan, G.Q. Zircon U-Pb, Molybdenite Re-Os and Quartz Vein Rb-Sr Geochronology of the Luobuzhen Au-Ag and Hongshan Cu Deposits, Tibet, China: Implications for the Oligocene-Miocene Porphyry-Epithermal Metallogenic System. Minerals 2019, 9, 476. [CrossRef]

27. Egbert, G.D.; Booker, J.R. Robust estimation of geomagnetic transfer functions. Geophys. J. R. Astron. Soc. 1986, 87, 173-194. [CrossRef]

28. Egbert, G.D. Robust multiple-station magnetotelluric data processing. Geophys. J. Int. 1997, 130, 475-496.

29. Chave, A.D.; Jones, A.G.; Mackie, R.; Rodi, W. The Magnetotelluric Method: Theory and Practice; Cambridge University Press: Cambridge, UK, 2012.

30. Groom, R.W.; Bailey, R.C. Decomposition of magnetotelluric impedance tensors in the presence of local three-dimensional galvanic distortion. J. Geophys. Res. Solid Earth 1989, 94, 1913-1925. [CrossRef]

31. Caldwell, T.G.; Bibby, H.M.; Brown, C. The magnetotelluric phase tensor. Geophys. J. Int. 2004, 158, 457-469. [CrossRef]

32. Egbert, G.; Kelbert, A. Computational recipes for electromagnetic inverse problems. Geophys. J. Int. 2012, 189, 251-267. [CrossRef]

33. Kelbert, A.; Meqbel, N.; Egbert, G.D.; Tandon, K. ModEM: A modular system for inversion of electromagnetic geophysical data. Comput. Geosci. 2014, 66, 40-53. [CrossRef]

34. Kruschwitz, S.; Yaramanci, U. Detection and characterization of the disturbed rock zone in claystone with the complex resistivity method. J. Appl. Geophys. 2005, 57, 63-79. [CrossRef]

35. Leng, C.-B.; Cooke, D.R.; Hou, Z.-Q.; Evans, N.J.; Zhang, X.-C.; Chen, W.T.; Danišík, M.; McInnes, B.I.A.; Yang, J.-H. Quantifying Exhumation at the Giant Pulang Porphyry Cu-Au Deposit Using U-Pb-He Dating. Econ. Geol. 2018, 113, $1077-1092$.

36. Zheng, Y.; Sun, X.; Gao, S.; Wang, C.; Zhao, Z.; Wu, S.; Li, J.; Wu, X. Analysis of stream sediment data for exploring the Zhunuo porphyry Cu deposit, southern Tibet. J. Geochem. Explor. 2014, 143, 19-30. [CrossRef]

37. Wan, X.-Q.; Sun, X. Apatite fission track thermochronology of Cenozoic igneous rocks from porphyry copper deposits in the Gangdese belt of southern Tibet: Implications for cooling history and ore preservation. Ore Geol. Rev. 2021, 133, 104075. [CrossRef]

38. Palacky, G.J. Geophysical methods in geology. Earth-Sci. Rev. 1988, 25, 87-89. [CrossRef] 